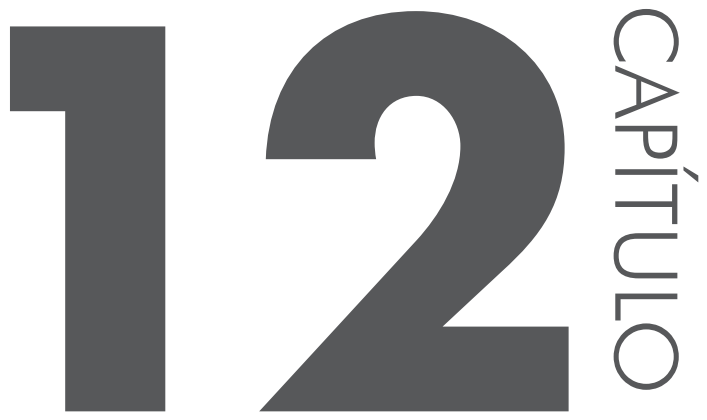

\title{
ENSINO DE GEOGRAFIA: MAPEANDO O ESPAC̣O COTIDIANO
}

Amanda Abadia Felizardo Custódio ${ }^{1}$

Odelfa Rosa ${ }^{2}$

Magda Valéria da Silva ${ }^{3}$

Resumo: O presente texto tem por objetivo reafirmar a importância da relação entre o ensino de Geografia na escola e os conhecimentos cartográficos por meio da aplicação de atividades didático-pedagógicas para alunos do $7^{\circ}$ ano do Ensino Fundamental ministrado no Colégio Estadual Maria das Dores Campos, alocado em Catalão/Goiás. A proposição dessas atividades é no sentido de que

1 Universidade Federal de Goiás/Regional Catalão, Brasil

2 Universidade Federal de Goiás/Regional Catalão, Brasil

3 Universidade Federal de Goiás/Regional Catalão, Brasil

E-mail de contato:amanda.custodio891@hotmail.com 
sejam utilizadas como recursos didáticos para auxílio no ensino-aprendizado da cartografia em sala de aula. A metodologia adotada perpassa a conciliação da teoria com a prática. Nesse caso, foram aplicados quatro tipos de atividades/ações de representação cartográfica realizadas em sala de aula. A primeira atividade refere-se à observação das aulas; a segunda foi uma atividade lúdica, conhecida como «cabra-cega» almejando apresentar os pontos cardeais; a terceira traz a representação espacial (mapa) do trajeto percorrido pelos alunos de casa até a escola; a quarta ação refere-se à construção da planta da sala de aula pelos alunos. Todas as atividades foram expostas e analisadas segundo critérios propostos por Almeida (2011). Para tanto, a pesquisa foca a importância do uso de aspectos do cotidiano do aluno para incentivar o processo de ensino-aprendizagem dos saberes cartográficos presentes na disciplina de Geografia.

Palavras-chave: Cartografia. Ensino. Geografia.

Abstract: This text designed to reinforce the importance of the relationship between the teaching of school geography and knowledge mapping from the application of didactic and pedagogical activities for students of the 7th grade of elementary school taught in State College Maria das Dores Campos, allocated in Catalao/Goias. The proposition of these activities is in the sense that they are used as teaching resources to aid in the teaching-learning of cartography in the classroom. The methodology pervades the reconciliation of theory and practice in this case were applied four types of activities/cartographic representation of actions carried out in the classroom. The first activity refers observation of classes; The second was a play activity, known as "blind man's buff" aiming to introduce the cardinal points; The third brings the spatial representation (map) of the route taken by the home to the school and students; The fourth action refers to the construction plan of the classroom by the students. All activities were exposed and analyzed according to criteria proposed by Almeida (2011). Therefore, the research focuses ma importance of using aspects of the student's daily life to encourage the teaching and learning of cartographic present knowledge in the discipline of school Geography.

Keywords: Cartography. Education. Geography.

\section{INTRODUC̣ÃO}

A Geografia, assim como outras disciplinas que fazem parte do currículo escolar do Ensino Fundamental e Médio, contribui para que o aluno possa desenvolver maior capacidade de observação, de análise, de interpretação e de pensamento crítico sobre as transformações socioespaciais. O ensino de geografia tem a tarefa de contribuir para que o aluno compreenda o espaço produzido pela sociedade em suas contradições, relações de produção e apropriação da natureza. Explicar como 
a sociedade produz e reproduz o espaço, o qual está em construção e transformação permanente, implica a necessidade de proporcionar aos alunos habilidades e competências para localização, orientação e representação. Essas habilidades são significativas para a compreensão do espaço geográfico e o estudo da cartografia oferece uma base teórico-metodológica para o entendimento desse espaço.

O presente texto traz resultados que estão consubstanciados no Trabalho de Conclusão de Curso, desenvolvido no ano de $2013^{4}$. O objetivo principal deste ensaio é apresentar a importância do vínculo do ensino escolar de Geografia com os conhecimentos da Cartografia por meio da aplicação de atividades didático-pedagógicas para alunos da $7^{a}$ série do Ensino Fundamental do Colégio Estadual Maria das Dores Campos, sediado em Catalão/Goiás.

A partir desse objetivo principal, desdobram-se os específicos: 1) apresentar aos alunos as noções básicas da cartografia em associação com o ensino escolar da Geografia como meio de conhecer o espaço e as transformações socioespaciais; 2) possibilitar aos alunos da escola um processo de familiarização com mapas, plantas, desenhos e outras representações cartográficas; 3 ) induzir o desenvolvimento, em sala de aula, de atividades didático-pedagógicas que proporcionem habilidades e conhecimentos das noções cartográficas e de sua aplicação no cotidiano dos alunos.

Tais objetivos almejam contribuir para que o aluno se torne um cidadão consciente das transformações do espaço que o circunda, sendo a linguagem cartográfica, um dos meios para isso. Porém, é importante dizer que, desde o início de sua escolaridade, o aluno não pode apenas aprender a ler, escrever e contar, mas deve aprender também a construir as primeiras noções de espaço e interpretá-las à luz de sua capacidade cognitiva, do conhecimento acumulado e da realidade vivida.

Dessa forma, a representação do espaço pode se dar por meio de representações gráficas e cartográficas como: cartas, plantas, croquis, mapas, globos, fotografias e imagens de satélites. São comunicações visuais importantes de estarem presentes constantemente na sala de aula, especialmente na disciplina de Geografia. A O ensino da linguagem cartográfica não deve se ater à simples cópia do mapa, mas também à construção de representações reais. Deve levar em consideração o conhecimento informal que o aluno traz de sua vida cotidiana e o conhecimento formal adquirido na escola.

4 Trabalho de Conclusão do Curso de Geografia Licenciatura pela Universidade Federal de Goiás - Regional Catalão intitulado "Cartografia na sala de aula: mapeando o espaço cotidiano com alunos do $7^{\circ}$ ano no Colégio Maria das Dores Campos, em Catalão (GO)". Orientadora: Prof. ${ }^{a}$ Dr. ${ }^{a}$ Odelfa Rosa. 
Em termos metodológicos, para a aquisição de informações que estão presentes neste texto, realizaram-se leituras, fichamentos, resumos, análises de livros e artigos que serviram de fonte sobre temas como: a) caracterização histórica da Geografia e da Cartografia; b) ensino da cartografia na escola e c) recursos didáticos para o ensino de cartografia. Dentre os autores consultados estão: Lacoste (1998), Machado (1999), Oliveira (1987), Castrogiovanni (2006), Almeida e Passini (2004), Almeida (2011), Castrogiovanni e Callai (2006) e Francischett (1999).

Ainda metodologicamente foram realizadas atividades de representação gráfica cartográfica com alunos da escola pesquisada, cujo tema escolhido foi "A cartografia e suas representações gráficas". Os alunos desenvolveram atividades didático-pedagógicas, divididas em quatro tipos de ações/atividades.

A primeira ação se deu mediante a observação das aulas de Geografia do $7^{\circ}$ ano do Ensino Fundamental, durante dois meses, uma aula por semana, com a finalidade de familiarização com o conteúdo e com os alunos pesquisados. A segunda ação refere-se à realização de uma atividade lúdica, conhecida popularmente como "cabra-cega", cujo objetivo é retomar o sentido de orientação no espaço, conforme indicam os pontos cardeais. A terceira atividade é concernente à representação espacial, com a construção de mapas do trajeto percorrido pelo aluno de casa até a escola. A quarta atividade refere-se à representação da sala de aula frequentada pelos alunos por meio da construção da planta do espaço. Destaca-se que os três tipos de atividades/ações foram expostas e analisadas segundo critérios propostos por Almeida (2011).

Portanto, propõe-se neste texto, apresentar a Geografia como uma disciplina que possui um leque extenso de possibilidades para a produção de atividades econômicas, políticas, sociais, espaciais, ambientais e culturais. No entanto, acredita-se que a utilização de métodos teóricos que sejam sem ligação com o cotidiano dos alunos tornam as aulas desestimulantes e 'desinteressantes' do ponto de vista deles. No caso, a cartografia pode ser um dos vieses que permite essa relação com o cotidiano do aluno, especialmente, por meio de atividades práticas em sala de aula, como a confecção manual de mapas e plantas pelos alunos. Como a sociedade está constantemente passando por transformações, o professor necessita estar a par dessas mudanças para ser um mediador dos conhecimentos que o aluno, aprendendo e apreendendo em sala de aula, aplicará em sua realidade.

\section{ENSINO DE GEOGRAFIA E A CARTOGRAFIA NA ESCOLA}

O ensino de Geografia acadêmico e escolar contempla, dentre outros, os saberes e as linguagens cartográficas, por isso, eles assumem um papel importante no processo de ensino-aprendizagem de Geografia. Os saberes cartográficos se fa- 
zem necessário à formação intelectual e cidadã dos alunos, mas ensinar cartografia não é uma tarefa muito fácil, assim como apreender a linguagem cartográfica também não é.

Os saberes e as linguagens da cartografia podem estar presente no dia a dia do aluno por meio da localização, da orientação, da representação dos dados socioeconômicos e naturais em mapas, representações gráficas e outros. No entanto, é preciso despertar neste aluno a curiosidade por esses saberes, é preciso estimular que ele relacione os conteúdos com a realidade vivida com o fim de desmitificar as dificuldades encontradas durante o curso da disciplina de Geografia.

Um dos conteúdos didáticos mais utilizado é o mapa. Essa representação gráfica é capaz de traduzir informações geográficas diversas, que precisam ser lidas, interpretadas e associadas à realidade de um dado momento. Para isso, o aluno precisa de uma formação inicial e básica que lhe permita realizar, de forma correta, as interpretações necessárias, e, dessa forma, assimilar os conteúdos presentes no mapa.

É preciso reconhecer que os mapas são as formas mais antigas de representação gráfica da humanidade. Oliveira (1987) relata em sua obra que: "Quaisquer que tenham sido os motivos, de um modo geral as culturas primitivas, antes mesmo de atingirem a fase da escrita, registraram com pedras, em cascas de árvores, no chão, em peles de animais etc., informações, conceitos e fatos através de sinais ou símbolos necessários à sobrevivência humana” (OLIVEIRA 1987, p. 2).

Os povos primitivos apresentavam sua organização no espaço por meio de representações que marcavam a forma como realizavam a manutenção das atividades essenciais e necessárias à sobrevivência. O desejo de demarcar o espaço e de representá-lo esteve presente desde a origem da vida em sociedade. Com o tempo, diversos povos acrescentaram suas contribuições para a evolução cartográfica, tais como: egípcios, chineses, gregos, romanos e, por fim, os portugueses.

Houve com o tempo o desenvolvimento de conhecimentos, técnicas e equipamentos que facilitaram a orientação, a localização e a produção de mapas. Desse modo, a Cartografia assumiu características um pouco mais modernas no século XVIII quando Estados Absolutistas da Europa decidiram fazer o mapeamento topográfico de seus territórios devido às constantes disputas territoriais. Vale ressaltar que essa cartografia de uso exclusivo de chefes de Estado e de militares é classificada como tradicional por se caracterizar pela preocupação única de produzir mapas.

A cartografia do século XIX representada principalmente por mapas serve como meio de orientação, de conhecimento e de ocupação de territórios, pois os mapas, ao apresentarem representações mais fidedignas, tornam-se mais confiáveis e mais usados para conhecer e ocupar territórios, inclusive fora da Europa. 
Alexander von Humboldt teve papel importante no desenvolvimento da cartografia durante a sua viagem ao continente americano, em especial à América do Sul, como afirma Thrower: "Quando da sua chegada à América do Sul elaborou um mapa da divisão das águas, entre as bacias do Orenoco e do Amazonas, e também um mapa dos Andes à Nova Espanha (México). A cartografia de Humboldt permitiu o avanço do conhecimento do globo com seu Atlas Geographique et Physique Du Nouveau Continent (Atlas Geográfico e Físico do Novo Continente)" (THROWER, 1991, p. 27 apud RIBEIRO; GHIZZO, 2012, p. 66).

A cartografia do século XIX apresentou avanços a respeito do conhecimento do globo terrestre, das regiões e dos povos, que possibilitaram o estabelecimento dos territórios por parte das potências europeias.

De acordo com Castrogiovanni (2006), no século XX, a cartografia alcança um novo momento e passa a ser considerada Cartografia Moderna, pois além de se preocupar com a produção dos mapas, também leva em consideração quem será o leitor do mapa. É nesse momento que os mapas atingem seu caráter mais "popular": as figuras cartográficas (mapas, cartas e plantas) passam a ser utilizadas em situações cotidianas como localização dos cursos de água, viagens turísticas, compra e venda de imóveis. Para Simielli (1999), a cartografia se preocupa atualmente com o usuário do mapa, com a mensagem transmitida e com a eficiência do mapa como elemento transmissor de informação.

A cartografia teve sua evolução relacionada às mais significativas transformações da sociedade e não pode ser entendida nem explicada fora do âmbito do processo de desenvolvimento das forças produtivas e das relações de produção, pois os conhecimentos cartográficos foram e ainda são importantes para o desenvolvimento do capitalismo.

Segundo Machado (1999), aprender cartografia para a Geografia é mais do que aprender regras de construir mapas, suas diferenças, o uso de cada tipo de produto, e, atualmente, técnicas computadorizadas. Isso é importante ser ensinado, mas só isso não é suficiente para o processo de ensino-aprendizagem em Geografia. É importante que o conhecimento cartográfico contribua para análises sociais, políticas, ambientais e culturais. Os mapas em especial podem apontar para um comprometimento com a sociedade e com a cidadania.

A representação gráfica cartográfica de mapas, plantas, desenhos, imagens e outros mais torna-se importante no processo de ensino-aprendizagem em Geografia, pois com a visualização das imagens representadas é possível despertar no aluno a capacidade de realizar leituras críticas e diversificadas e, ainda, possibilitar ao aluno associar a representação com fatos e acontecimentos do passado e da atualidade. Nesse sentido, a representação cartográfica contribui para a formação dos alunos, mas essa deve estar associada a bases científicas e teóricas 
possibilitadas pela Geografia, ou seja, a cartografia, por si só, não permite aos alunos um aprofundamento dos saberes sobre o espaço e suas transformações, pois a leitura e a compreensão da imagem visual dependem sistematicamente da contribuição da ciência geográfica.

Para Oliveira (1987), a cartografia contribui com a Geografia ao comunicar os fenômenos ocorridos por meio de mapas que os tornam visíveis e possíveis de serem e interpretados mediante leitura e análise da representação. A Geografia, por sua vez, analisa como os elementos físicos e biológicos se organizam no espaço, enquanto a cartografia mostra a disposição desses elementos. Nota-se que há uma relação dialética significativa entre a Geografia e as noções de cartografia, uma depende da outra. A Geografia é uma ciência e a cartografia, uma técnica ou ferramenta que permite a interpretação de imagens visuais do espaço.

Para orientar, perceber as distâncias, localizar e compreender os fenômenos, o indivíduo precisa ler o espaço ao seu redor e não apenas observar mapas. Diante disso, a cartografia é considerada uma linguagem relevante para a aprendizagem da Geografia ao permitam escrever e ler as características do espaço, mas a análise da imagem visual depende das contribuições conceituais da geografia.

A cartografia é uma ferramenta ou técnica que pode ser utilizada praticamente em todos os conteúdos da Geografia, não apenas para a localização espacial, mas para entender as relações entre os fatos, fenômenos e acontecimentos. O aluno precisa pensar e analisar o espaço e sua produção para estar apto a elaborar mapas em suas várias formas de representação e fazer uso das escalas, legendas, símbolos e signos.

Os Parâmetros Curriculares Nacionais (PCN) de Geografia destaca a importância da utilização da linguagem cartográfica: "O estudo da linguagem cartográfica tem cada vez mais reafirmado sua importância, desde o início da escolaridade. Contribui não apenas para que os alunos venham a compreender e utilizar uma ferramenta básica da Geografia, os mapas, como também para desenvolver capacidades relativas à representação do espaço" (BRASIL, 1998, p. 118).

Lacoste (1998) ressalta que os alunos vão à escola para aprender a ler, escrever e contar, mas não vão à escola para aprender a ler um mapa. Para Passini (1994), a educação cartográfica para a leitura de mapas deve ser considerada tão importante quanto a alfabetização para a leitura da escrita. Com interesse de esclarecer a importância de desenvolver aspectos do domínio espacial e de sua representação, Almeida e Passini (2004) afirmam que:

A territorialidade implica a localização, a orientação e a representação dos dados socioeconômicos e naturais, que contribuem para a compreensão da totalidade do espaço. [...] Localização/orientação/representação são, portanto, conhecimentos, habilidades integrantes do processo de trabalho e são utilizados de forma diferenciada, 
já que o trabalho também é diferenciado de acordo com a organização da sociedade. No ensino elementar, esses conhecimentos/habilidades devem ser desenvolvidos e aprofundados desde a $1^{\circ}$ até a $8^{\circ}$ séries, na medida em que são essenciais ao estudo da Geografia (ALMEIDA; PASSINI, 2004, p. 12).

Segundo Castrogiovanni (2006) aprender a ler um mapa pode contribuir para a formação de um cidadão autônomo ao possibilitar seu deslocamento em diferentes espaços comuns, ou não. Ler e escrever em Geografia exigem, além do domínio de conteúdos teóricos, também o domínio da linguagem cartográfica,. Para que o aluno o adquira é preciso que ele aprenda a construir representações do espaço. Segundo Almeida (2011), um aluno, para chegar a ver uma representação do espaço como possibilitadora de estudos geográficos, precisa entender os problemas que um cartógrafo encontra para elaborar um mapa, isto é, antes de ser um decodificador ele precisa ser um codificador.

Já de acordo com Passini (1994), o aluno precisa confrontar as questões que um cartógrafo encontra: projeção, escala, simbologia e localização. É necessário propor ao aluno situações que o façam vivenciar as funções de um cartógrafo para que ele possa se transformar em leitor de mapa. Porém, para que tais habilidades e competências sejam possíveis, o aluno necessita de uma base de conhecimentos geográficos iniciais.

A educação cartográfica em seu processo de ensino-aprendizagem na disciplina de Geografia na escola geralmente fica limitada ao uso dos mapas e do globo em sala de aula. O uso de apenas essas duas técnicas de ensino acaba limitando o foco de apreensão dos fenômenos espaciais, resumindo-os à preocupação com contornos. Almeida e Passini (2004) ressaltam que:

A ação para que os alunos entendam a linguagem cartográfica não está em pintar e copiar contornos, mas em "fazer o mapa" para que, acompanhando metodologicamente cada passo do processo - reduzir proporcionalmente, estabelecer um sistema de signos ordenados, obedecer a um sistema de projeções para que haja coordenação de pontos de vista (descentralização espacial) -, familiarize-se com a linguagem cartográfica (ALMEIDA; PASSINI, 2004, p. 22).

O aluno ao construir um mapa deve conseguir apreender de forma real os fenômenos e os processos geográficos, históricos e estatísticos que podem ser cartografados via representação gráfica e simbolica do mapa. Ao construir um mapa, o aluno fará escolhas, assim como usará símbolos e signos para representá-las, mas para tal ele precisa conhecer minimamente os saberes e as linguagens da cartografia

Almeida (2011) destaca ainda que são poucos os estudos a respeito da "Alfabetização Cartográfica", mesmo que todos os educadores concordem que aprender a ler um mapa é necessário para a formação básica do aluno. Utilizar os mapas 
como recursos pedagógicos deve estar incluído desde o início da alfabetização escolar, para que exista uma gradativa familiarização com conceitos básicos que permita aos alunos se tornarem leitores eficientes de mapas e de suas representações.

Portanto, pode-se concluir que é necessário que o uso dos mapas e demais representações gráficas seja utilizado desde o início da escolarização para que os alunos cheguem às próximas fases do ensino como leitores críticos e mapeadores conscientes. É imprescindível que a escola, como agente propulsor de conhecimento, trabalhe o espaço de forma contextualizada e significativa, ou seja, de forma que o aluno possa aplicar esse conhecimento em sua realidade e que esse conhecimento faça sentido em seu cotidiano. A prática, os métodos, a metodologia adotados em sala de aula não podem ser separados da realidade social e vivenciada pelo aluno.

\section{OBJETIVO}

\subsection{Objetivo geral}

Apresentar a importância de relacionar o ensino de Geografia com os conhecimentos de cartografia a partir da aplicação de atividades didático-pedagógicas para alunos da $7^{a}$ série do Ensino Fundamental do Colégio Estadual Maria das Dores Campos, sediado em Catalão/Goiás.

\subsection{Objetivos específicos}

1) Apresentar aos alunos as noções básicas da cartografia em associação com o ensino da Geografia como meio de conhecer o espaço e suas transformações;

2) Possibilitar aos alunos da escola pesquisada um processo de familiarização com mapas, plantas, desenhos, croquis e outras representações cartográficas;

3) Induzir o desenvolvimento, em sala de aula, de habilidades, de conhecimento das noções cartográficas e de suas aplicações no cotidiano do aluno por meio de atividades didático-pedagógicas.

\section{METODOLOGIA}

Os procedimentos metodológicos abordados neste texto estão baseados na metodologia construída e desenvolvida no Trabalho de Conclusão do Curso de Geografia Licenciatura pela Universidade Federal de Goiás - Regional Catalão intitulado "CARTOGRAFIA NA SALA DE AULA: mapeando o espaço cotidiano com alunos do $7^{\circ}$ ano no Colégio Maria das Dores Campos, em Catalão (GO)". 
A construção textual, a execução dos objetivos e as reflexões somente foram possíveis mediante a adoção de procedimentos metodológicos pertinentes à temática central. Os procedimentos se dividem em três etapas articuladas teoricamente.

$\mathrm{Na}$ primeira etapa, foi realizada revisão da literatura sobre o ensino de Geografia e o ensino da cartografia no sistema educacional básico, recorreu-se bibliografia especializada como: livros, teses e dissertações, artigos científicos e textos diversos. Essa etapa contribuirá para compreender: a caracterização histórica da geografia e da cartografia; a importância do ensino da cartografia na escola e o uso de recursos didáticos cartográficos em sala de aula. Dentre os autores selecionados destacam-se: Lacoste (1998), Machado (1999), Oliveira (1987), Castrogiovanni (2006), Almeida e Passini (2004), Almeida (2011), Callai (2006) e Francischett (1999).

A segunda etapa consiste no planejamento da intervenção na escola, o qual estabeleceu quatro ações distintas. A primeira ação se deu mediante a observação das aulas de Geografia do $7^{\circ}$ ano do Ensino Fundamental, durante dois meses, uma aula por semana para que houvesse uma familiarização com o conteúdo e com os alunos. Findadas as observações e feitas as ponderações necessárias, teve-se início as intervenções práticas para a realização e a aplicação das atividades didático-pedagógicas, cujo tema escolhido foi “A cartografia e suas representações gráficas”.

A segunda ação se deu mediante a realização de uma atividade lúdica conhecida como "cabra-cega". A turma pesquisada foi dividida em dois grupos, meninas e meninos, ambos teriam que escolher um representante que ficaria com os olhos vendados, o qual teria que recolher as peças espalhadas pelo chão seguindo as orientações dos integrantes do grupo a que pertencia. A locomoção dos representantes deveria basear-se pela orientação dos pontos cardeais (sul, norte, leste, oeste). Ao fim da brincadeira, quem tivesse recolhido maior número de peças, ganharia o jogo.

A terceira ação contemplava os elementos importantes que devem estar presentes numa representação gráfica cartográfica (plantas, mapas, croquis etc.). Para apreensão desses elementos, foi solicitada aos alunos a produção de um mapa que representasse o trajeto que eles percorriam de casa até a escola.

A quarta ação se deu por meio da produção de uma planta da sala de aula realizada pelos alunos.

E por fim, a terceira etapa metodológica consiste na tabulação das informações coletadas e na análise dessas informações que deram origem ao Trabalho de Conclusão de Curso supracitado, sendo que parte dessa análise está presente neste texto. Portanto, a análise das atividades desenvolvidas, a associação das noções de Geografia com as noções cartográficas adquiridas pelos alunos e como elas se apresentam nas atividades serão melhor detalhadas na sequência. 


\section{RESULTADOS E DISCUSSÃO}

Nesta seção, serão realizadas análises dos resultados provenientes das atividades didático-pedagógicas aplicadas à turma do $7^{\circ}$ ano do Colégio Estadual Maria das Dores Campos.

A aplicação das atividades didático-pedagógicas à turma do $7^{\circ}$ ano foi desenvolvida a partir de quatro ações, sendo que a primeira refere-se a observação de aulas da disciplina de Geografia da turma pesquisada; a segunda é concernente a realização de uma atividade lúdica com alunos - cabra-cega - como objetivo de verificar se os alunos tinham noção de localização e orientação, conforme os pontos cardeais ensinados em sala de aula; a terceira ação foi solicitado que os alunos realizaram o mapeamento do trajeto que percorrem diariamente de casa até a escola, redundando em mapas e; a quarta ação destinou-se a produção de uma planta da sala de aula que os alunos estudam na escola pesquisada.

Deve-se ressaltar, em primeiro lugar, que é muito importante que os alunos tenham acesso às condições que lhe permitam associar a teoria e a prática nas diversas temáticas propostas pelo ensinos de Geografia e de cartografia. No que diz respeito às noções de cartografia, os espaços do cotidiano do aluno assumem grande importância no processo de ensino-aprendizagem, pois concordamos com Francischett (1999) quando destaca que a sala de aula, a escola, a casa e todos aqueles espaços que as crianças conhecem do ponto de vista de sua distribuição espacial, constituem boas escolhas para que elas façam a representação gráfica em desenhos, plantas, mapas ou croquis.

E para que essas atividades venham a ter resultados positivos, é preciso que o professor se posicione e questione as produções dos alunos, avaliando a forma, o tamanho, a posição, a orientação, a distância, a direção e a produção dos objetos e locais representados, de maneira a contribuir para que os alunos construam noções cartográficas. Portanto, ajudar o aluno a construir uma leitura do espaço em que está inserido é fundamental para que ele compreenda a realidade do seu entorno e a associe aos conteúdos escolares.

$\mathrm{Na}$ busca de levar os alunos do $7^{\circ}$ ano a associar os seus espaços de vivência cotidiana aos saberes e linguagens da cartografia apreendidos em sala de aula na disciplina de Geografia, foram solicitadas a realização de atividade lúdica de orientação no espaço e a produção de desenhos de alguns espaços que lhes são familiares em seu dia a dia, isto é, o mapa do trajeto de casa até a escola e a planta da sala de aula em que estuda. As análises das quatro atividades didático-pedadógicas serão relatadas a seguir. 


\subsection{Atividade lúdica}

$\mathrm{Na}$ turma do $7^{\circ}$ ano do Colégio Estadual Maria das Dores Campos, com objetivo de desenvolver as ações da segunda etapa da proposta metodológica, foi realizada a primeira ação didático-pedagógica, que se refere à observação das aulas de Geografia, durante dois meses, uma aula por semana; tal ação foi tomada para que houvesse uma familiarização com o conteúdo e com os alunos. Finalizada a etapa das observações e feitas as ponderações necessárias, tiveram início as intervenções práticas para a aplicação das atividades didático-pedagógicas, cujo tema escolhido foi "A cartografia e suas representações gráficas”.

A segunda ação proposta destinou-se à realização de uma atividade lúdica conhecida como "cabra-cega". Essa ação se deu da seguinte forma: a turma foi dividida em dois grupos, meninas e meninos, ambos teriam que escolher um representante que ficaria com os olhos vendados para recolher as peças espalhadas pelo chão, sob as orientações dos integrantes do seu grupo. A locomoção dos representantes deveria basear-se na orientação dos pontos cardeais (norte, sul, leste, oeste). Os grupos deveriam se ater a seguir algumas indicações, por exemplo: dois passos para o norte, dois passos para o sul ou um passo para o leste, vire para o oeste etc. Quem fizesse uso das indicações de direita e esquerda, para trás e para frente perderia duas peças. No fim da brincadeira, quem tivesse recolhido maior número de peças, ganharia o jogo.

Após o fim da dinâmica, foi possível perceber que os alunos dessa turma tiveram dificuldades em se locomover segundo a orientação dos pontos cardeais, mesmo que, antes de terem os olhos vendados, tenham recebido indicações em sala de aula sobre quais são os pontos cardeais.

Entretanto, Moreira (1999) corrobora com tal pensamento ao afirmar que atualmente a educação tem sido questionada quanto à eficácia de métodos utilizados por professores que buscam alternativas visando facilitar a aprendizagem do aluno. Dentre as metodologias mais eficazes está a utilização de jogos e de brincadeiras como uma das pontes de ligação entre o aluno e o conhecimento.

Após finalização dessa atividade, partiu-se para as duas ações finais que envolvem noções cartográficas, como, por exemplo, a construção de desenhos manuais de mapas e de plantas.

\subsection{Mapa do trajeto escola/casa}

A leitura da paisagem que faz parte da vivência do aluno é uma proposta do ensino da Geografia, como consta no PCN de Geografia. Pensando nisso, será feita, na sequência, uma análise dos desenhos produzidos pelos alunos do $7^{\circ}$ ano do Colégio Estadual Maria das Dores Campos, durante o período de coleta de 
informações. As intervenções em sala de aula foram pensadas e executadas de forma gradativa, com o fim de desenvolver a pesquisa em discussão neste texto.

Para dar sustentação à realização da terceira etapa da pesquisa, a ação solicitada aos alunos tinha como objetivo que eles construíssem mapas do trajeto de casa até a escola. Para tal, foi realizada uma aula expositiva sobre o histórico da cartografia e de seus usos, além de se indicar como os pontos cardeais poderiam auxiliar na vida cotidiana dos alunos. Concluídas as aulas expositivas, passou-se à atividade referente à confecção de um mapa do trajeto de casa para a escola, que necessitou dos seguintes materiais: régua, lápis de cor, lápis de escrever, borracha, canetas coloridas e folha tamanho A3.

Para o desenvolvimento dessa atividade, precisou-se de um número significativo de aulas. No início, os alunos mostraram-se desinteressados por não entenderem a necessidade da produção dos mapas. Vale destacar que os alunos tinham entre 12 e 14 anos. Nessa faixa etária, os adolescentes apresentam resistências às iniciativas diferenciadas, mas foi possível concluir essa ação com êxito.

A proposta da construção de mapas, desenhados manualmente pelos alunos participantes da pesquisa, almeja reforçar as noções cartográficas tão presentes no ensino da disciplina de Geografia, mas também levá-los a dar-se conta de como essas noções são importantes no cotidiano deles.

A proposta de que os alunos desenhassem ou mapeassem o trajeto de casa à escola, deve-se à intimidade e à proximidade que eles possuem com esse trajeto, por percorrê-lo diariamente.

Dessa maneira, os desenhos tornam-se recursos didáticos que podem ser valorizados e utilizados pelos professores não somente da disciplina de artes, mas também podem ser um importante recurso para as aulas de Geografia, principalmente se o tema estiver relacionado à cartografia. O mapeamento do trajeto que o aluno percorre todos os dias de casa até a escola e/ou da escola até sua residência é um recurso didático em que é possível trabalhar a noções de localização, orientação e proporção no processo de aprendizagem dos alunos.

A respeito disso, Almeida (2011) afirma que, ao desenhar, a criança e o jovem representam seu modo de pensar o espaço, o desenho não é só a cópia de objetos, mas a interpretação do real e da realidade de um dado momento. O mapa também é o recorte de uma realidade, dessa forma, o mapeamento desse trajeto é uma visão/observação realizada pelo aluno de uma realidade que lhe é inerente e presente em seu cotidiano. Cabe destacar que no ambiente escolar os alunos precisam ser incentivados a desenhar, como forma de desenvolverem referências de orientação espacial, requisitos fundamentais para o entendimento de mapas, tão presentes na disciplina de Geografia. 
Segundo Paganelli (1999), os professores das séries iniciais do Ensino Fundamental utilizam frequentemente o recurso do desenho, mas de repente há o abandono desse recurso nas séries seguintes, quando os professores de geografia tentam introduzir os mapas prontos. O que se observa é que existe uma lacuna entre uma fase e outra, ou seja, o uso dos desenhos é interrompido, mas depois é exigida uma leitura de desenhos prontos, que não foram feitos pelos alunos. Isso pode levar a uma dificuldade no processo de ensino-aprendizagem em Geografia e ainda à estigmatização dos conteúdos que se referem às noções de cartografia. Uma alternativa, para suprir tal lacuna, pode se dar inicialmente com os alunos aprendendo a mapear o que está a sua volta, para posteriormente entenderem os saberes e as linguagens da cartografia como requer o ensino formal.

Com o fim de minimizar essa dificuldade propôs-se que os alunos realizassem desenhos ou mapas do trajeto percorrido por eles de casa até a escola onde estudam. Portanto, nessa terceira atividade/ação proposta, foi solicitado aos alunos que fizessem um mapa do trajeto (desenho) que percorrem de casa até a escola. Tais mapas desenhados manualmente estão apresentados nas Figuras 1, 2,3 e 4 .

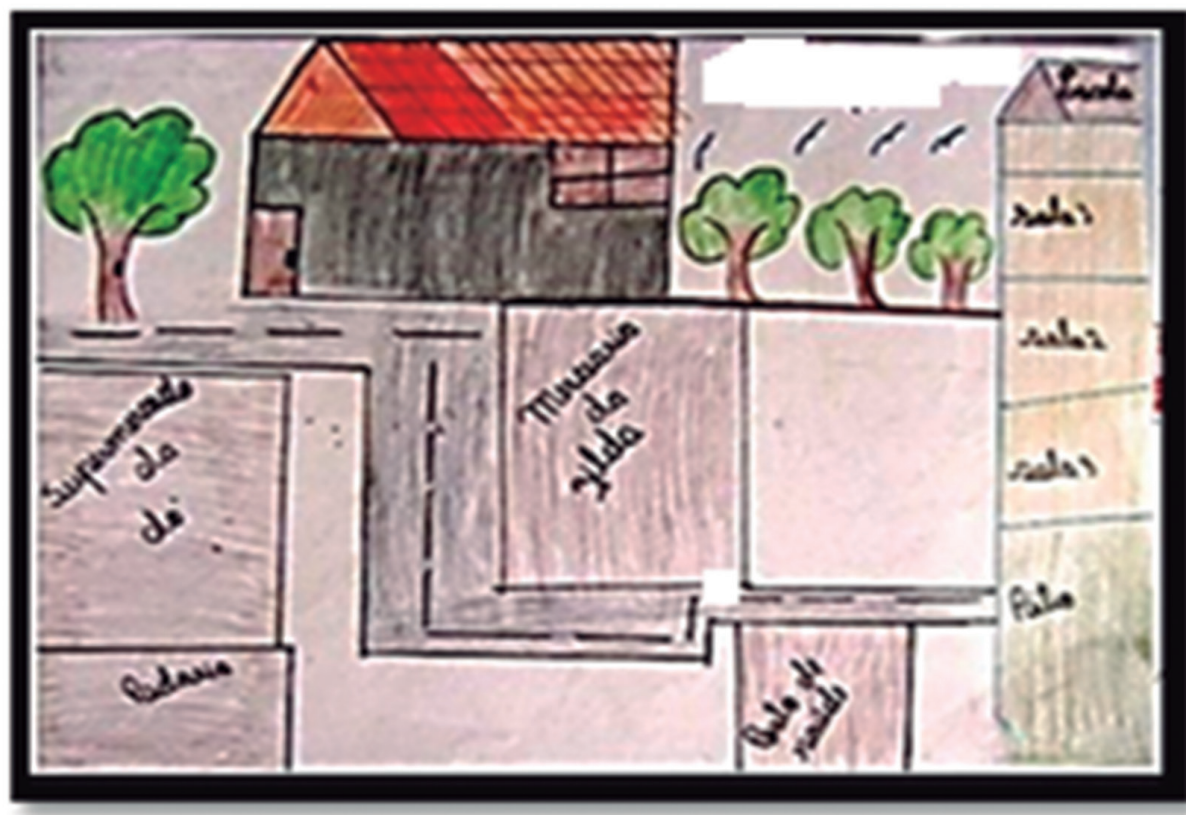

Figura 1. Mapa do trajeto casa/escola.

Especificamente na Figura 1 destaca-se a presença de árvores em diferentes quantidades e tamanhos, além de alguns pontos de referência como comércios e a 
quadra poliesportiva. É possível verificar o uso de diferentes visões na construção do desenho, sendo: vertical, frontal e lateral.

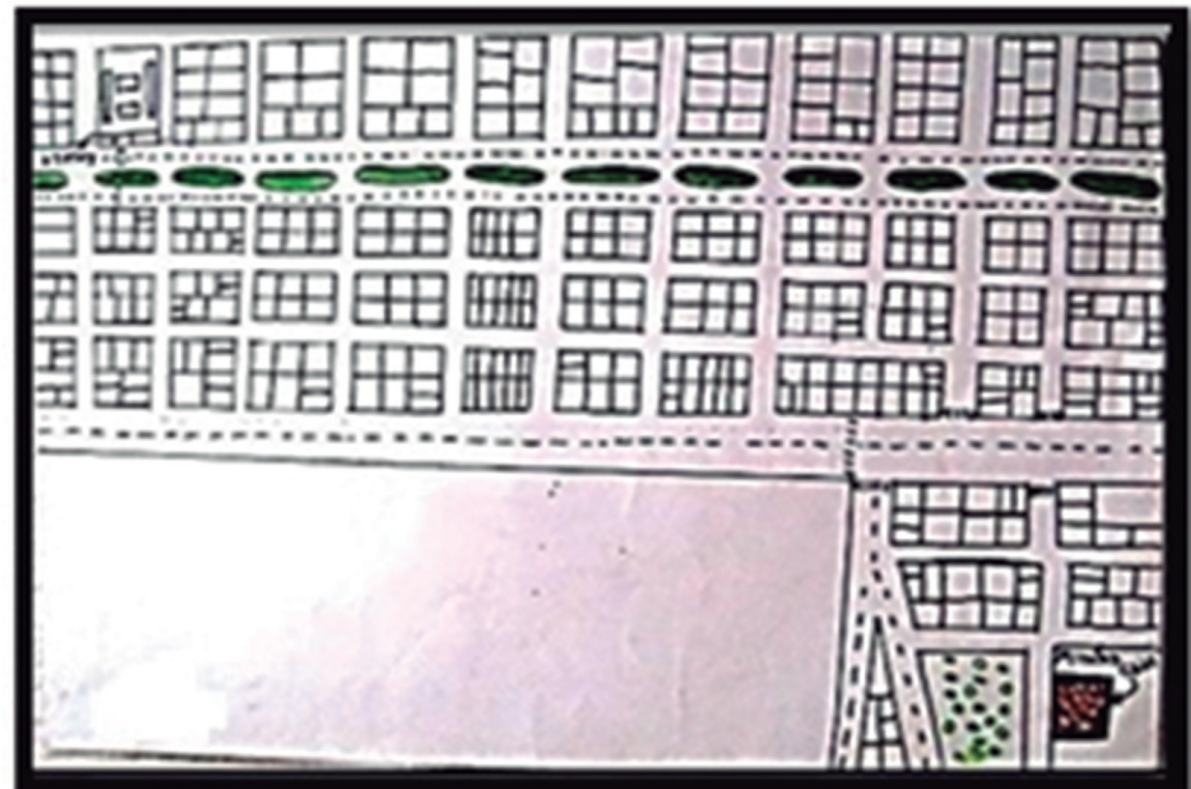

Figura 2. Mapa do trajeto casa/escola (visão vertical).

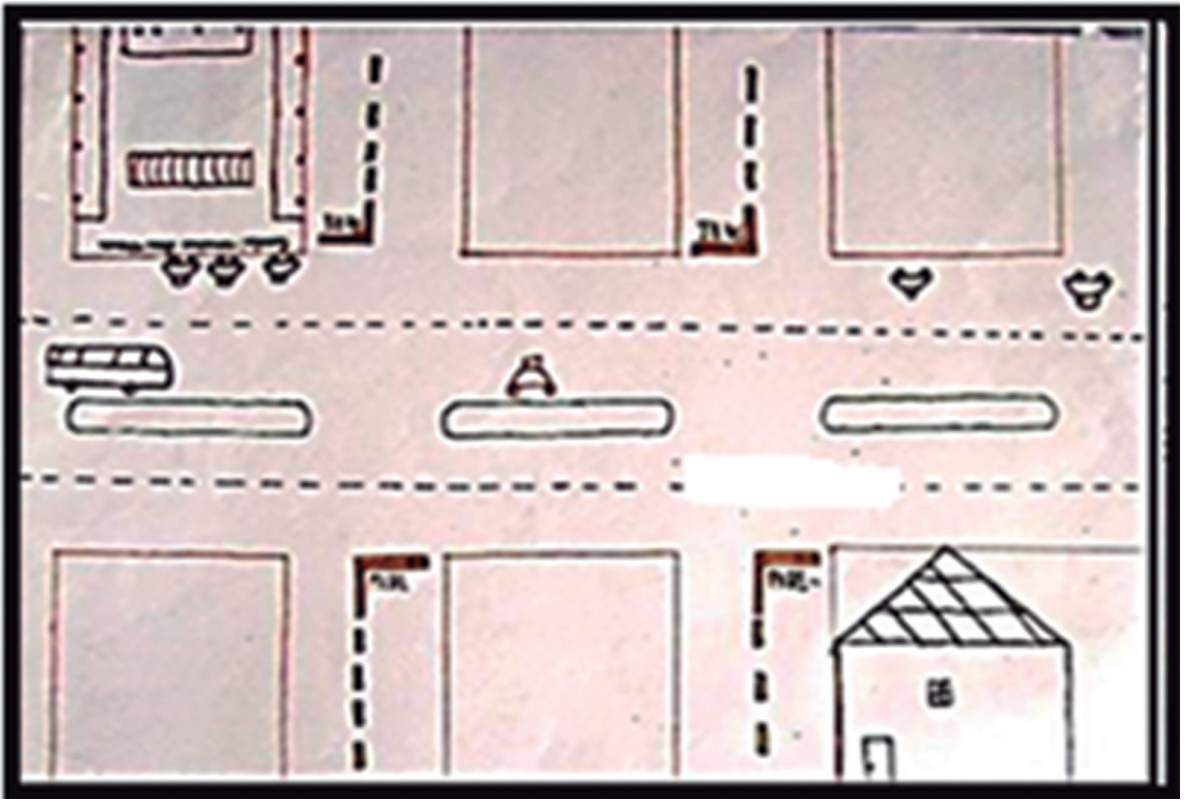

Figura 3. Mapa do trajeto casa/escola (visão horizontal e vertical). 


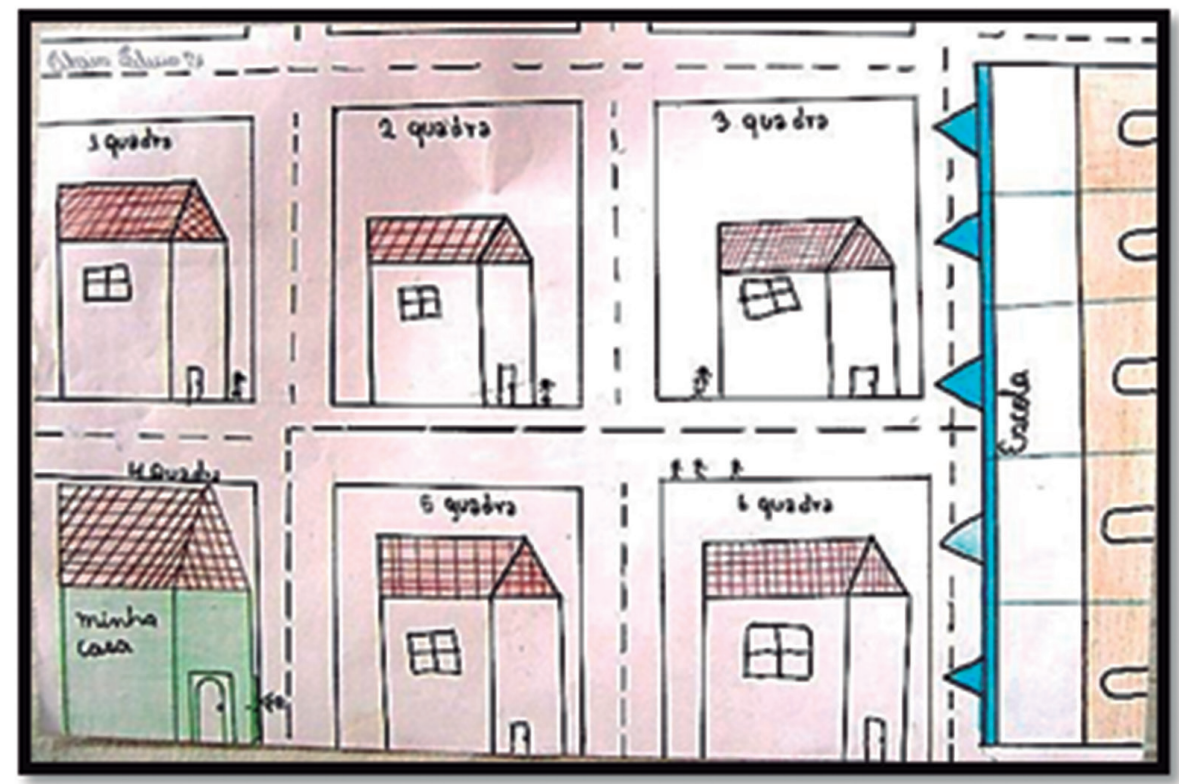

Figura 4. Mapa do trajeto escola/casa (visão horizontal).

Já nas Figuras 2, 3 e 4 observa-se a presença predominante de elementos humanizados, com destaque para a localização de suas casas e da escola. Quanto às visões se caracterizam pela mistura de horizontais e verticais.

Para Almeida (2011), existem cinco aspectos que precisam ser observados nos desenhos produzidos: localização, proporção, simbologia, projeção e leitura dos arredores. Esses aspectos denotam um conhecimento inicial dos saberes e das linguagens cartográficas por parte dos alunos, mas que precisam ser incentivados em sala de aula.

Com a conclusão dos desenhos dos alunos, foi feita uma exposição na própria escola durante o horário do intervalo entre os dois blocos de aulas (recreio). Nessa exposição, os alunos puderam apreciar suas produções e também as produções dos demais colegas. O propósito da exposição foi fazer com que os alunos observassem atentamente os desenhos, proporcionando uma conversa entre eles sobre o que representaram, como representaram e o que pensam sobre os espaços com os quais se relacionam diária e diretamente. Essa atividade também facilitou a observação e a identificação dos diferentes estágios de desenvolvimento das relações espaciais e do modo como os alunos as capturam e apreendem.

Ao fazer uma análise geral dos desenhos/mapas do trajeto casa/escola feito pelos alunos considerando os aspectos apontados por Almeida (2011), é possível observar que a simbologia foi totalmente deixada de lado, pois nenhum dos desenhos apresentou algum tipo de legenda para explicar o que foi representado. 
Quanto à proporção dos elementos representados nos desenhos em comparação ao tamanho real deles, nota-se que em nenhuma das Figuras (2, 3 e 4), os alunos levaram em consideração o elemento proporção, embora alguns até tenham tentado mantê-la, porém, ficou distante do indicado como ideal.

A respeito da localização, avaliou-se a construção dos desenhos (Figuras 2, 3 e 4) em relação ao caminho percorrido e como ocorre o posicionamento dos elementos representados em relação à rua. Nesse caso específico, constata-se que os alunos conseguiram ser exatos quanto à localização da escola, enquanto os demais elementos foram dispostos sem uma sequência lógica no que se refere à localização.

$\mathrm{O}$ aspecto da projeção tem como objetivo analisar a visão escolhida pelo aluno para construir o desenho. Nas Figuras 2, 3 e 4 verificam-se três tipos de visão: lateral, vertical e frontal/horizontal; porém, a Figura 2 traz uma visão vertical; a Figura 3 traz duas visões simultâneas na representação, sendo vertical e horizontal, e a Figura 4 aponta uma visão horizontal.

E por último, o aspecto de ler os arredores também é um elemento importante a ser analisado nas Figuras 2, 3 e 4. Alguns alunos não tiveram nenhuma preocupação com os arredores, representando somente sua casa e uma rua que a ligava diretamente com a escola (Figura 2). No entanto, outros representaram árvores, carros, pessoas, estabelecimentos comerciais (Figuras 1, 3 e 4), tendo inclusive a preocupação de colocar pontos de referência no trajeto desenhado. Além desses aspectos considerados, durante a exposição dos desenhos dos alunos, notou-se a ausência de uso de elementos básicos para a compreensão de um mapa como: título, orientação, escala e legenda.

Dessa forma, as Figuras 1, 2, 3 e 4 trazem um pouco dessa representatividade espacial na concepção dos alunos da escola pesquisada. Esses desenhos representam a leitura da paisagem a qual eles tem acesso, contêm elementos, símbolos e contornos a serem interpretados e trazem um pouco do conhecimento cartográfico acumulado ao longo do tempo, mediante o saber geográfico adquirido no ensino formal (escolar).

\subsection{Plantas da sala de aula}

A quarta e última ação pedagógica das atividades propostas pela segunda etapa metodológica da pesquisa teve como objetivo requerer dos alunos que eles construíssem um desenho ou planta de um espaço familiar, cotidiano e de representatividade sociocultural. Sendo assim, foi solicitada a construção da planta da sala de aula que eles frequentam diariamente.

A escolha da sala de aula deve-se a dois fatores principais: 1) é uma área de convívio comum de todos os alunos do $7^{\circ}$ ano, permitindo uma reflexão comum 
e/ou diferente entre os alunos sobre o espaço conhecido, vivenciado e recorrente a todos; 2) a construção de uma planta não é tarefa fácil e a sala de aula por ser um espaço pequeno facilitaria aos alunos representar detalhes relevantes na construção de plantas.

Nesse viés, Callai (2003) afirma que os espaços cotidianos jamais devem ser esquecidos nas aulas de geografia, eles precisam ser retomados e reinterpretados, criando possibilidades de pensar em contextos mais amplos. É importante o uso do espaço existencial para que os alunos construam seus saberes a respeito do lugar em que vivem.

De acordo com Castrogiovanni (2006), o intuito de uma atividade como esta é demonstrar aos alunos que as representações podem receber nomenclaturas distintas, dependendo da escala e dos elementos. Dessa forma, as plantas servem para identificar ou mapear áreas de dimensão menor, mas que apresentam uma escala grande. Essas condições são ideais para encontrar no produto cartográfico uma riqueza de detalhes que escapam nos mapas, porque se refere a áreas grandes em escalas pequenas.

Feitas todas essas considerações, foram dadas as condições necessárias para o desenvolvimento da última atividade de aprendizagem sobre os conteúdos cartográficos, na qual os alunos deveriam desenhar "A planta da sala". Considerando que ficaram claros, nas aulas expositivas, quais os elementos são importantes para elaboração de uma planta e de um mapa, foi proposto aos alunos que fizessem uma representação da sala de aula que frequentam (planta).

Para desenvolver essa atividade em sala de aula, primeiro, o aluno deve se localizar nesse espaço, utilizando como referência o local onde está sentado. Por meio da observação, o aluno identificará o que tem a sua esquerda, a sua direita, à frente e atrás e como os demais elementos da sala estão dispostos. Em seguida, são retiradas as medidas da sala de aula e de seus principais elementos para se estabelecer as escalas possíveis. A partir daí os alunos têm a liberdade para iniciar a construção de suas representações.

Reforçando a importância de construir plantas, especialmente, de espaços pequenos e de relação cotidiana do mapeador, Almeida (2011) afirma que essas qualidades fazem da sala de aula um lugar espacial relevante para um trabalho de representação gráfica do espaço.

Para realização dessa atividade foram utilizados os seguintes materiais: lápis de cor, lápis de escrever, canetas coloridas, borracha, régua, calculadora, fita métrica e folha sulfite A3. Antes de iniciar as atividades, os alunos mediram todos os elementos da sala: carteiras, porta, janela, paredes e quadro. Depois utilizaram a calculadora para transformar as medidas reais da sala em medidas próprias para uma representação em um plano, havendo assim um processo de produção das 
escalas. Nas Fotos 1 e 2 pode ser visualizado o momento de produção da planta da sala de aula.

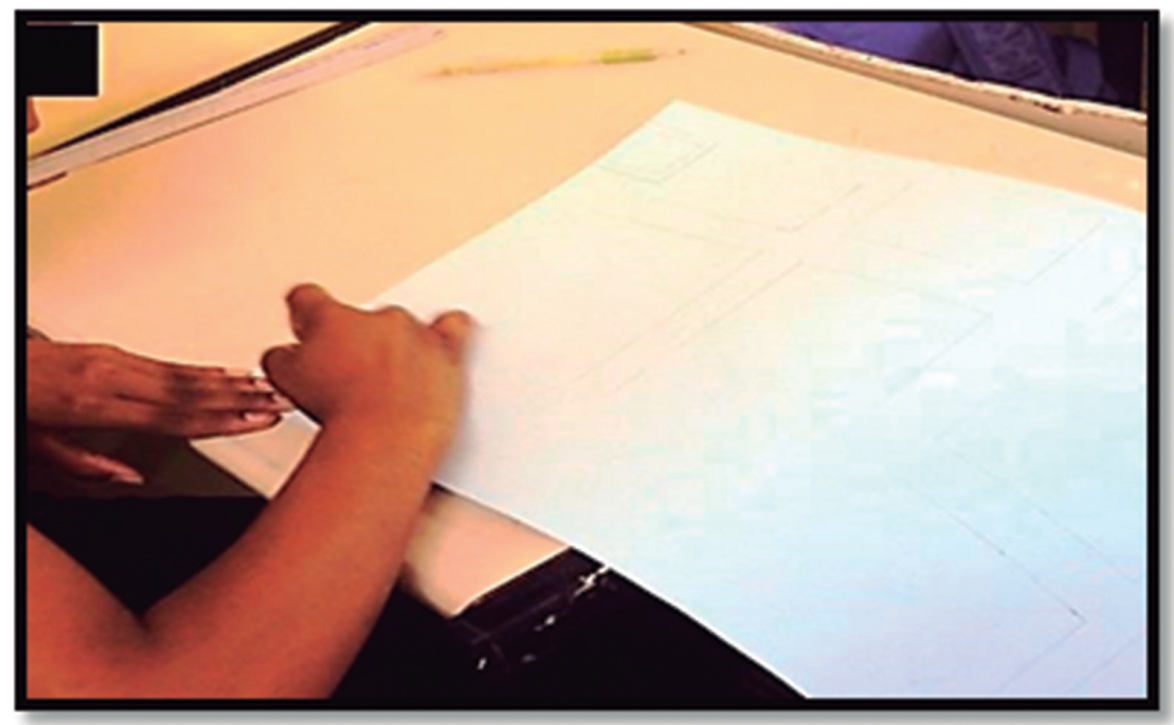

Foto 1. Alunos produzindo a planta da sala de aula.

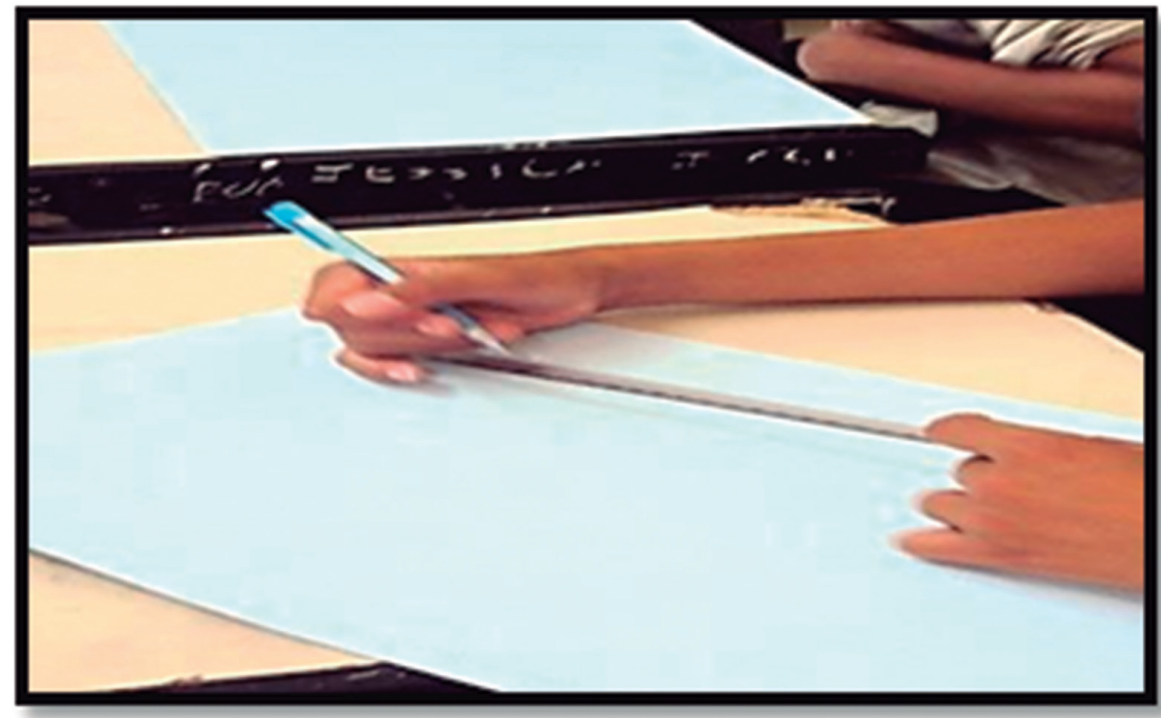

Foto 2. Alunos construindo a planta da sala de aula.

Ao construir esse modelo reduzido da sala de aula, os alunos se defrontaram com as questões de proporção, redução e localização. Na Foto 2, pode ser obser- 
vado que a régua foi um instrumento presente na produção da planta, levando em consideração a proximidade da cartografia com as noções matemáticas.

Estas atividades realizadas durante as aulas tiveram como objetivo levar os alunos a entender, ler e interpretar os mapas para desenvolver uma aproximação inicial com as noções cartográficas, que, por sua vez, são evitadas pela dificuldade de interpretação de plantas e de mapas. Os mapas devem apresentar título, escala, informações visuais e textuais, legenda, símbolos e seus significados, fontes, coordenados geográficas e outros elementos. Já as plantas também podem apresentar parte desses elementos, mas desde que a escala seja grande e a área cartografada seja pequena, essas são condições essenciais para identificar uma planta.

Considerando que os alunos já tiveram acesso e conhecimento dos elementos necessários para construção de um mapa e de uma planta, como resultado foram obtidos diferentes desenhos. Seleciona-se alguns para observações mais acuradas, os quais podem ser vistos nas Figuras 5, 6 e 7.

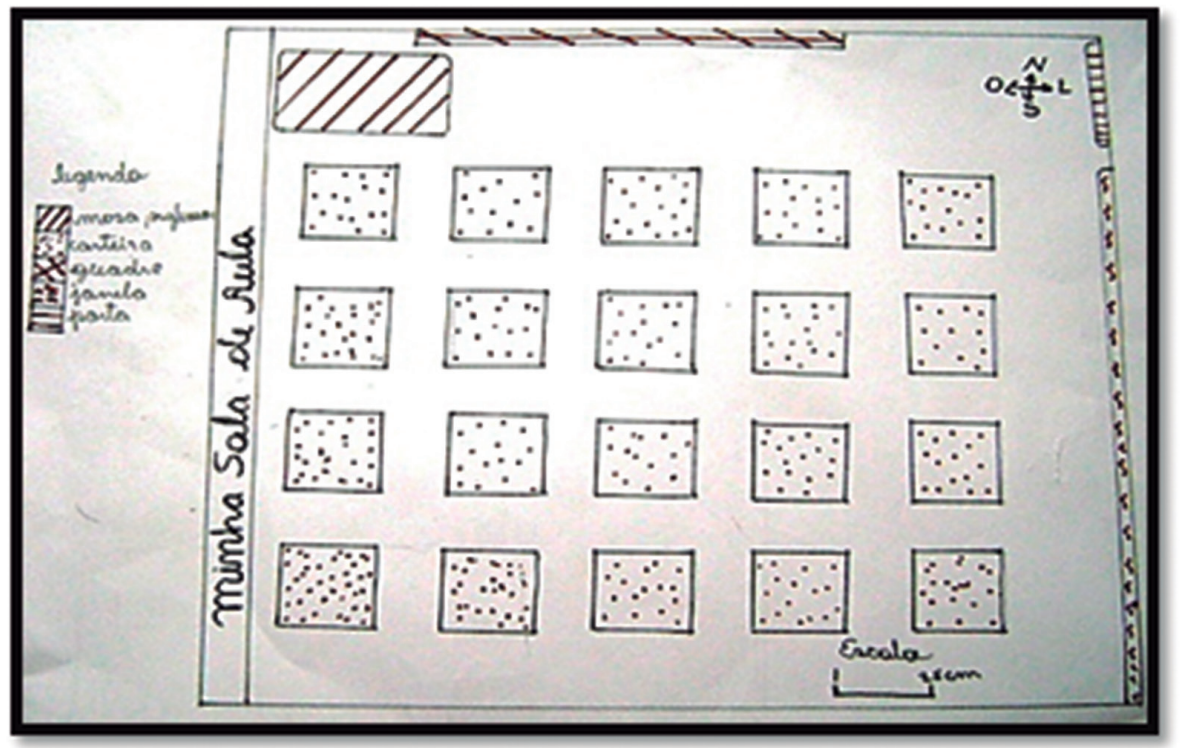

Figura 5. Planta da sala de aula.

No geral, os desenhos das plantas apresentaram semelhanças na forma de organização dos elementos da sala, se diferenciando na disposição das informações como: uso de cores, números e símbolos zonais. Nota-se que as atividades desenvolvidas até então ainda não foram suficientes para que os alunos produzissem com perfeição suas representações, que contassem com a presença de elementos essenciais à identificação de uma representação cartográfica (título, orientação, escala, coordenadas geográficas, legenda). 


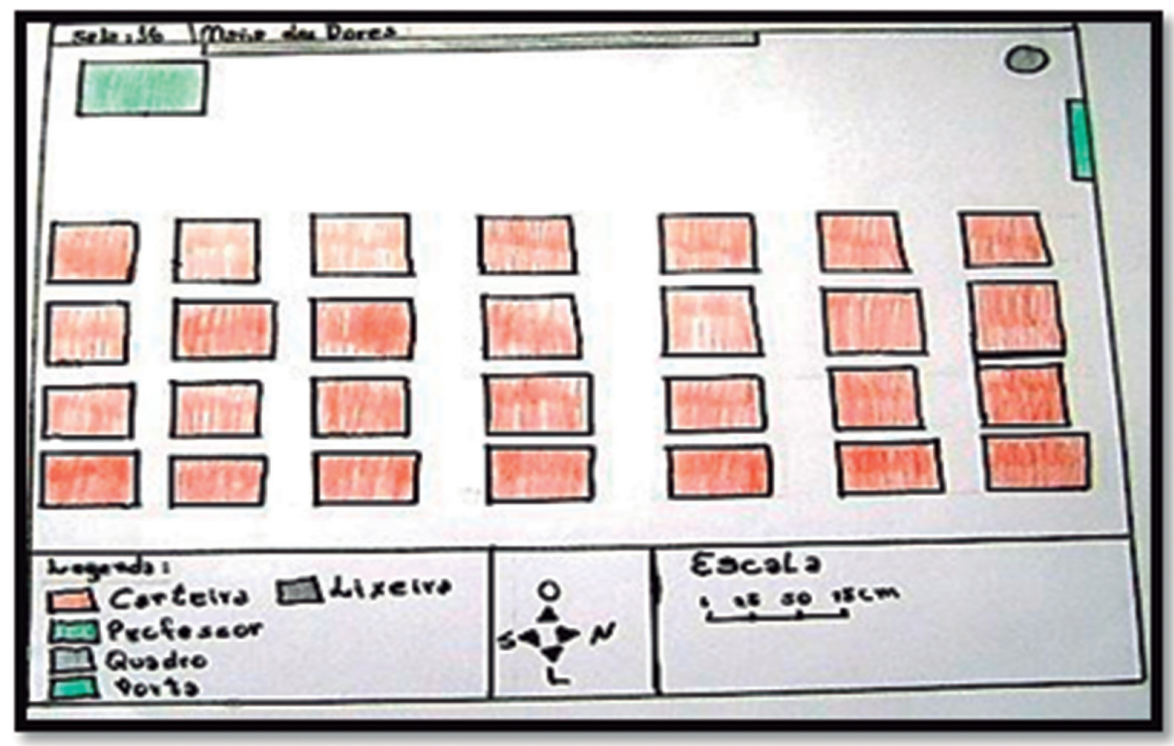

Figura 6. Planta da sala de aula.

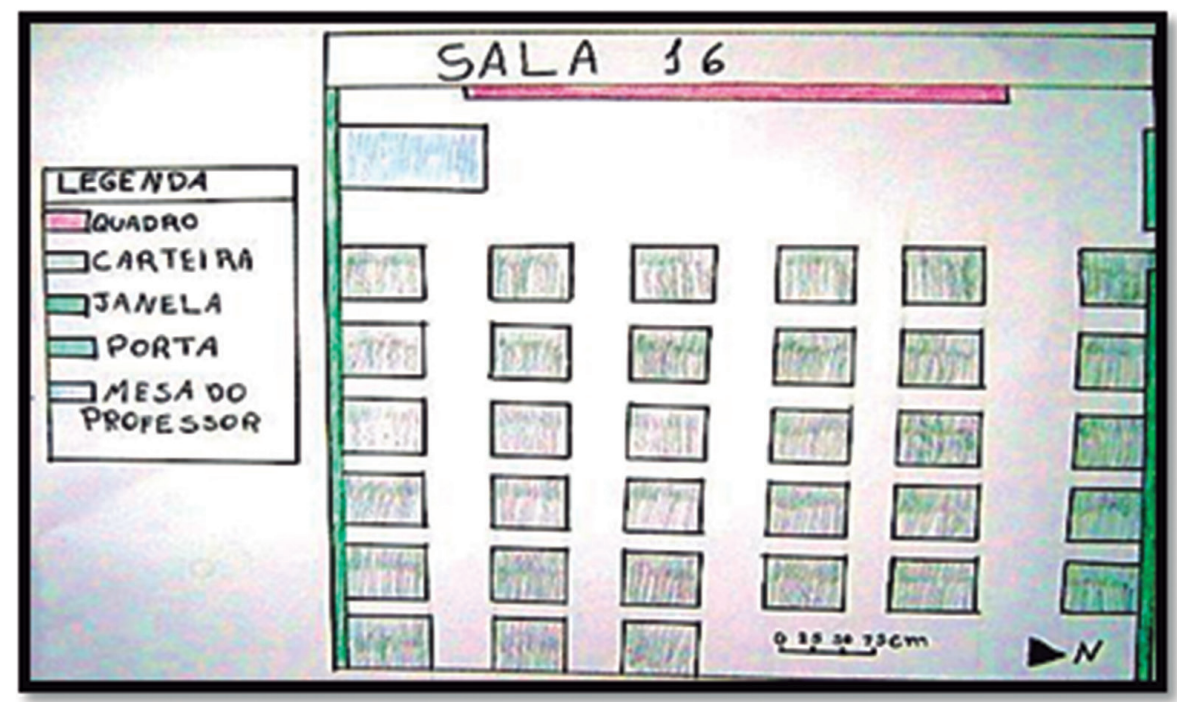

Figura 7. Planta da sala de aula.

As três plantas (ver Figuras 5, 6 e 7) apresentam escalas gráficas, no entanto, nota-se uma desproporcionalidade ou mesmo ausência de elementos nessas plantas cartografadas pelos alunos do $7^{\circ}$ ano do Colégio Estadual Maria das Dores Campos. A Figura 6 não apresenta as janelas da sala de aula; na figura 7 faltam cadeiras dispostas; a projeção da escala gráfica na Figura 5 está diferente das constatadas nas Figuras 6 e 7. 
Novamente houve uma exposição dos desenhos das plantas para que os alunos tivessem contato com outras formas de observar o mesmo espaço. A exposição dos desenhos das plantas permitiu a comparação e promoveu ainda o estímulo para que novas atividades sejam apreendidas e detalhadas por parte dos alunos. Segundo Almeida (2011), é importante que os alunos vivenciem situações nas quais comparem informações representadas em diferentes tipos de mapas, de plantas e de cartas topográficas e estabeleçam relações entre fenômenos variados. Nesse processo levar em consideração o cotidiano relacionado à cartografia torna-se um recurso didático importante para que os alunos percebam a geografia a sua volta.

Nesse limiar, para Almeida (2011), a linguagem cartográfica, como conteúdo geográfico, desperta a percepção espacial e proporciona no aluno o entendimento sobre o espaço que habita. A cartografia representa um recurso e uma ferramenta importante para o ensino da geografia, pois permite a representação de diferentes recortes do espaço na escala que convém para o ensino. Dessa maneira, a cartografia possibilita ao aluno entender a maneira pela qual ele está inserido no espaço, que pode ser local, regional, nacional e global. Já Callai (2003) acrescenta que pensar o espaço supõe dar ao aluno condições de construir um instrumento, não apenas para entender determinado conteúdo, mas para usá-lo como possibilidade de construir a sua cidadania.

Contudo, a atividade proposta e desenvolvida na escola pesquisada contribuiu para identificar a base inicial dos alunos em termos de conhecimento cartográfico, além disso, estimulou a apreensão dos conteúdos geográficos, de forma a relacioná-los a processos, situações e condições vividas no cotidiano do ambiente escolar e da sociedade como um todo.

\section{CONCLUSÃO}

A cartografia é um instrumento importante à disposição do professor de geografia, como recurso metodológico. Geografia e cartografia juntas objetivam propor reflexões e práticas que levem o aluno a compreender o espaço que o circunda e no qual possa atuar. É visto que as abordagens que levam em consideração a cartografia ainda não alcançaram sua verdadeira relevância no ambiente escolar, ocorrendo ainda de forma insatisfatória.

O grande desafio dos professores de geografia tem sido despertar no aluno a curiosidade pelo conhecimento. E o que se tem visto nas escolas diariamente são as dificuldades com alunos desinteressados, a imposição do livro didático ao professor e a ausência de recursos por parte da escola para buscar alternativas metodológicas. O resultado desse ensino são aulas expositivas cansativas baseadas no pressuposto de que os professores são os detentores do saber e os alunos depósitos de conhecimento. 
Especificamente, na disciplina de Geografia, observa-se a dificuldade dos alunos a respeito da linguagem cartográfica, sendo preciso destacar que as atividades propostas se baseavam em conteúdos já ministrados em outras aulas. A intenção da proposta de atividades didático-pedagógicas relatadas neste texto foi de apresentar a alternativa de as aulas teóricas ou expositivas serem intercaladas com aulas práticas, mas sem deixar de lado os conteúdos teóricos, que são de grande importância para o ensino de qualquer disciplina, porém não devem ser tidos como único recurso.

A utilização de atividades lúdicas e de desenhos foi uma forma de apresentar a geografia de uma maneira mais atraente aos alunos. Os desenhos manuais de mapas e plantas, além de facilitarem a visão do conhecimento que o aluno tem do espaço que habita, também proporcionam ao aluno uma interação com o processo de produção de uma representação gráfica cartográfica que compreende a transferência do espaço real para um plano.

Em resumo, a educação cartográfica se torna vazia quando ocorre por meio de cópias de mapas e plantas. Para superar isso, o aluno pode aprender a fazer uso desse recurso mediante a produção própria de mapas e plantas de espaços de seu cotidiano como: casa, escola, rua, sala de aula etc. Sobretudo, a cartografia possibilita a representação dos diferentes recortes do espaço em formas que forem interessantes para o ensino, seja a confecção de plantas, de mapas ou de cartas topográficas. Sendo assim, a cartografia se fundamenta na leitura e representação do espaço, permite visualizar de forma ampla os espaços e pode levar o aluno a entender onde e como ele se insere no espaço em sua dimensão local, regional, nacional ou global.

A construção e a leitura de um mapa ou planta não é tarefa simples para quem não possui o costume. Essas habilidades devem ser construídas durante todo o período de escolaridade mediante a proposição de exercícios e atividades pedagógicas que proporcionem análises e reflexões a respeito da leitura do espaço.

Constata-se que o mapeamento por parte do aluno é uma prática que deve se tornar constante no processo de ensino cartográfico, pois, como mapeador, o aluno terá condições de compreender as dificuldades de se confeccionar uma planta, um mapa ou uma carta topográfica, e ainda terá maior facilidade de ler e interpretar essas e outras representações gráficas cartográficas.

Contudo, este texto objetivou trazer a tona uma pouco das dificuldades relativas aos conteúdos didáticos de cartografia presentes na geografia ensinada na escola e ainda, para superar tais dificuldades, propôs o desenvolvimento de atividades práticas em sala de aula que buscassem tornar esses conteúdos interessantes aos alunos e lhes permitisse apreendê-los mediante a produção de mapas e plantas. 


\section{REFERÊNCIAS}

ALMEIDA, R. D. Do desenho ao mapa: iniciação cartográfica na escola. 4. ed. São Paulo: Contexto, 2011. 120 p.

ALMEIDA, R D.; PASSINI, E. Y. O espaço geográfico: ensino e representação. 5. ed. São Paulo: Contexto, 2004. 90 p.

BRASIL. Secretaria de Educação Fundamental. Parâmetros curriculares nacionais: história/geografia. Brasília, MEC/SEF, p. 118, 1998. Disponível em: <http://portal.mec. gov.br/seb/arquivos/pdf/livro052.pdf>. Acesso em: 7 jun. 2015.

CALLAI, H. C. A formação do profissional da geografia. 2. ed. Ijuí: Unijuí, 2003. 80 p. CASTROGIOVANNI, A. C.; CALLAI, H.; KAERCHER, N. A. Ensino de Geografia: práticas e textualizações no cotidiano. Porto Alegre: Mediação, 2006. 398 p.

FRANCISCHETT, M. N. A Cartografia no ensino de Geografia: construindo os caminhos do cotidiano. ANAIS..., Curitiba - 18 a 13 de jul. de 1999.

LACOSTE, Y. A Geografia: isso serve, em primeiro lugar, para fazer guerra. Tradução Maria Cecília França. Campinas: Papirus. 1998.

MACHADO, E. A infocartografia. Geousp, n. 3, set.1999. São Paulo: Humanistas, 1999. MINISTÉRIO DA EDUCAÇÃO, SECRETARIA DE EDUCAÇÃO MÉDIA E TECNOLÓGICA. Parâmetros Curriculares Nacionais: Ensino Médio. Brasília: Ministério da Educação, 1999.

MOREIRA, M. A. Teorias de aprendizagem. São Paulo: EPU, 1999.

OLIVEIRA, W. S. Fundamentos e didática da Geografia I.Salvador: Nupre, 1987. (Coleção Formando Educadores).

PAGANELLI, T I. Cartografia no Ensino Fundamental e Médio. In: CARLOS, A. F. A. (Org.). A Geografia em sala de aula. São Paulo: Contexto, 1999. (Repensando o Ensino). PASSINI, E. Y. Alfabetização cartográfica e o livro didático: uma análise crítica. Belo Horizonte: Editora Lê, 1994.

RIBEIRO, V. H.; GHIZZO, M. R. Geografia e Cartografia: breve contextualização histórica. Revista Percurso, Maringá, v. 4, n. 1, p. 61-83, 2012. Disponível em: <file:///C:/Users/Magdaueg/Downloads/17027-70471-1-PB\%20(1).pdf>. Acesso em: 05 dez 2015.

SIMIELLI, Maria Elena. Ramos. Cartografia no Ensino Fundamental e Médio. In: CARLOS, Ana Fani Alessandri. (Org.). A Geografia em sala de aula. São Paulo: Contexto, 1999. 